\title{
ATUAÇÃO DE COOPERATIVAS DE CATADORES DE MATERIAIS RECICLÁVEIS NA LOGÍSTICA REVERSA EMPRESARIAL POR MEIO DE COMERCIALIZAÇÃO DIRETA
}

\author{
Fernanda Santos Mota de Jesus \\ Mestre em Administração de Empresas - Eaesp/FGV \\ fersmjesus@gmail.com
}

\begin{abstract}
José Carlos Barbieri
Professor adjunto do Departamento de Administração da Produção e Operações FGV/Eaesp-POI jose.barbieri@fgv.br
\end{abstract}

\section{RESUMO}

Esta pesquisa objetivou compreender a inserção de organizações de catadores, em programas empresariais de logística reversa, para reciclagem de embalagens pós-consumo. $O$ estudo multicasos englobou programas empresariais nos quais as cooperativas atuam como fornecedoras da primeira camada dos seguintes setores: vidro, papelão, embalagem longa vida e plástico PET. Este estudo envolveu quatro empresas e quatro cooperativas de catadores, uma delas analisada como explanação rival. De maneira geral, observou-se que as características dos programas decorrem das motivações para a estruturação da logística reversa, como, por exemplo: responsabilidade socioambiental, recuperação de materiais, competitividade da embalagem, imagem corporativa ou pelas compras de materiais secundários. Além da obtenção de escala e regularização, o avanço das cooperativas de catadores nessas cadeias de suprimentos foi viabilizado por meio da aprendizagem prática quanto à correta identificação e seleção de materiais recicláveis e desenvolvimento de processos de pré-processamento para garantia de qualidade, conforme exigências das empresas. Em dois dos casos analisados, constatou-se a atuação de empresas de bens de consumo na gestão de fluxos de informações, permitindo uma gestão eficiente das operações de logística reversa. Para as cooperativas de catadores analisadas, a comercialização direta tem proporcionado melhores preços dos materiais recicláveis e perspectivas de vendas em longo prazo.

Palavras-chave: Cooperativas de catadores; Embalagens pós-consumo; Logística reversa; Materiais recicláveis; Reciclagem; Recuperação de produtos e materiais.

\section{ACTING OF SCAVENGERS COOPERATIVES IN REVERSE LOGISTICS BUSINESS PROGRAMS THROUGH DIRECT COMMERCIALIZATION}

\begin{abstract}
This research aims to understand the inclusion of scavengers cooperatives in business programs to recycle post-consumer packages by reverse logistics. The multi-case study involved programs considering cooperatives advancement in reverse chain as first layer suppliers in the following sectors: glass, cardboard, long life packages and PET. The research was conducted with four companies and four cooperatives of collectors; one of them was analyzed as a rival explanation. It was observed that program characteristics are functions of a firm's motivations to implement reverse logistics, such as social and environmental responsibility, material recovery, packaging competitiveness, and branding or secondary materials purchases. Besides scale and regularization, the advancement of scavengers cooperatives in these supply chains has been made possible by "learning by doing" to identify and select recyclable materials and pre-processing process development for quality assurance in accordance with business requirements. The information flow management performed by consumer goods was found in two cases. This allows for a more efficient reverse logistics operations. These programs provide best recyclable materials prices and long term sales prospects for cooperatives.
\end{abstract}

Key words: Post-consumer packaging; Product recovery and materials; Recycling; Reverse logistics; Scavenger's organizations. 


\section{INTRODUÇÃO}

Os resíduos sólidos gerados após o consumo de bens e serviços pela população em geral constituem um dos problemas mais graves para o poder público local, a quem cabe dar destinação adequada e representam um enorme desperdício de recursos naturais. A recuperação desses resíduos nas formas de reuso, reciclagem e revalorização energética aumenta a vida útil dos aterros sanitários e reduz o custo da coleta de lixo doméstico. Ao mesmo tempo, contribui para aumentar a sustentabilidade do Planeta ao diminuir a necessidade de extração de recursos naturais para atender as necessidades de produção de bens e serviços demandados pela sociedade.

No Brasil, o incremento na geração de resíduos sólidos per capita, entre os anos de 2009 e 2010, foi de 5,3\% (Abrelpe, 2010). Somente na região Sudeste do Brasil são geradas 81.980 toneladas diárias de lixo urbano (Brasil, 2011). Práticas de logística reversa têm sido implantadas visando a recuperação de produtos e materiais por meio do reuso e da reciclagem. Entre os motivos que impulsionam essas práticas estão, por exemplo, as limitações acerca da disposição final de resíduos sólidos em aterros sanitários, o surgimento de legislações ambientais mais restritivas, o incremento da utilização de bens descartáveis, a adoção de estratégias empresariais de redução da utilização de recursos naturais e as possibilidades de reaproveitamento de materiais e/ou produtos para agregação de valor.

Este artigo apresenta os resultados de uma pesquisa que procurou responder a seguinte questão: como as organizações de catadores estão sendo inseridas em programas empresariais de logística reversa, por meio da comercialização direta, para recuperação de embalagens pósconsumo? Para isso foi realizado um estudo de casos múltiplos, envolvendo quatro empresas compradoras de materiais reciclados de quatro cooperativas de catadores. Este estudo se justifica pela importância que vem sendo dada aos catadores e as suas organizações em diversos instrumentos de política pública, como a regulamentação da profissão de catador e as iniciativas governamentais para promover a criação de cooperativas e associações.

Os sistemas de logística reversa são apontados como instrumentos da Política Nacional de Resíduos Sólidos - PNRS, instituída pela Lei 12.305/2010, podendo ser operacionalizados pelos fabricantes, importadores, distribuidores e comerciantes dos produtos em parcerias com cooperativas, ou outras formas de associação de catadores (Brasil, 2010). Essa lei adotou uma política inclusiva quanto à atuação das organizações de catadores na gestão de resíduos sólidos no que se refere à recuperação de resíduos pós-consumo. Daí a importância de conhecer como eles estão inseridos nas cadeias reversas das empresas que usam materiais coletados pelas organizações de catadores.

\section{OS CATADORES DE MATERIAL RECICLADO E A COLETA DE MATERIAL PÓS- CONSUMO}

Segundo a Agenda 21, fruto da Conferência das Nações Unidas sobre Meio Ambiente e Desenvolvimento, realizada no Rio de Janeiro em 1992, para a gestão ambientalmente adequada dos resíduos sólidos, as abordagens devem ultrapassar a simples disposição final segura, exigindose a aplicação do conceito de gestão do ciclo de vida de produtos de maneira a conciliar desenvolvimento econômico e preocupação ambiental (Unced, 1993). Ao se levar em consideração que a recuperação de produtos e materiais visa a minimização de resíduos enviados aos aterros (Nakashima et al., 2002) e o incremento da vida do produto (Jayaraman et al., 1999), essa premissa torna-se elemento estratégico para a gestão de resíduos sólidos. Tal abordagem no gerenciamento de resíduos gera valor adicional pelo surgimento de novas cadeias de suprimentos que reusam e reciclam materiais (Hicks et al., 2004). Para Dowlatshahi (2010), além de contribuir para a conservação de recursos naturais, a recuperação de produtos e materiais pós-consumo pode criar oportunidades de negócios rentáveis, representando uma alternativa para a geração de renda e trabalho por meio das cadeias de suprimento que fazem uso da logística reversa.

Entre os atores envolvidos na logística reversa de material pós-consumo no Brasil, destacase o papel do catador de material reutilizável e reciclável na recuperação de produtos e materiais

Revista de Gestão Social e Ambiental - RGSA, São Paulo, v. 7, n. 3, p. 20-36, out./dez., 2013. 
(Leal et al., 2003; Aquino et al., 2009; Gonçalves-Dias, 2009; Paula et al., 2010). Popularmente conhecido como "catador de recicláveis", "catador de sucata" e "agente ambiental", a profissão foi regulamentada como "catador de material reciclável" na Classificação Brasileira de Ocupações (CBO), em 2002 (MTE, 2002). A fim de evitar redundância e facilitar o entendimento será utilizada a terminologia simplificada "catador(es)".

O diálogo entre organizações de catadores e a iniciativa privada é destacado como alternativa para a consolidação de uma cadeia de reciclagem ambientalmente adequada e socialmente justa e inclusiva (Mota, 2005; Bunchaft, 2007). Assim, as empresas que incluem as organizações de catadores como fornecedoras de matérias são alvos potenciais para o fortalecimento dessas organizações (Mota, 2005; Torres, 2008; Gtz, 2010). Paula et al. (2010) também enfatizam o papel das organizações de catadores e a consolidação de programas empresariais de logística reversa.

No Brasil, estima-se que haja cerca de um milhão de catadores, considerando tanto os cooperativados quanto os autônomos (Cempre, 2013). Os catadores organizam-se em cooperativas e associações para "quebrar" o ciclo vicioso da pobreza (Medina, 2000), valorizar a profissão de catador (Mota, 2005), adquirir legitimidade na sociedade (Wilson et al., 2006), ter os direitos reconhecidos (Aquino et al., 2009), melhorar a renda (Gonçalves-Dias, 2009; Bid, 2010) e diminuir a dependência de intermediários (Wilson et al., 2006; Gonçalves-Dias, 2009; Bid, 2010). Porém, ainda são várias as barreiras encontradas pelas organizações de catadores para agregação de valor aos materiais coletados, como a falta de capital de giro (Ribeiro e Besen, 2007), a falta de qualificação profissional (Besen et al., 2006; Gonçalves-Dias, 2009), de recursos materiais e tecnológicos (Ribeiro e Besen, 2007; Gonçalves-Dias, 2009), instabilidade de renda (Besen et al., 2006; GTZ, 2010) e fragilidade na organização interna (Besen et al., 2006; Gonçalves-Dias, 2009).

As cooperativas e associações de catadores tiveram início no final da década de 1980 nas cidades de São Paulo, Porto Alegre e Belo Horizonte. Nas décadas seguintes, essas organizações foram aos poucos sendo inseridas em programas municipais de coleta seletiva. Em 2001, com a articulação dos catadores e uma rede de apoio formada por outras organizações civis, formou-se o Movimento Nacional dos Catadores de Materiais Recicláveis - MNCR. Em 2003, a inclusão dos catadores alcançou a agenda governamental nacional, tendo como marco a criação do Comitê Interministerial de Inclusão Social de Catadores de Materiais Recicláveis (Pereira e Teixeira, 2011).

Depois de 20 anos de trâmite para aprovação, a PNRS representa um avanço na gestão de resíduos sólidos, pois prevê a responsabilidade compartilhada sobre a gestão dos resíduos pósconsumo no país e a "[...]integração das cooperativas de catadores como prestadores de serviços para as atividades de logística reversa implantadas pelas empresas" (Demajorovic e Migliano, 2013, p. 65). Sendo assim, além da inclusão em políticas públicas, constata-se o estímulo dessa lei à participação das organizações de catadores em programas do setor empresarial.

Quanto à relação comercial com as empresas, a pesquisa de Sousa et al. (2012), ao analisar cooperativas de catadores do Programa de Coleta Seletiva do município de São Paulo, concluiu que, mesmo organizados, os catadores são dependentes dos intermediários para a comercialização dos materiais recicláveis. Entretanto, os autores afirmam que parcerias com empresas possibilitam o desenvolvimento dessas organizações. As empresas podem criar vínculos com as cooperativas tanto como produtoras, doando materiais recicláveis em troca dos serviços de coleta pelas cooperativas; ou quanto consumidoras, comprando diretamente das organizações de catadores (Instituto Ethos, 2007).

Os setores que apresentam destaque na cadeia de reciclagem no Brasil são os de alumínio, papel, vidro e plástico (Abrelpe, 2010). Segundo dados da Associação Brasileira de Alumínio (Abal, 2013), a relação entre o peso reciclado e o consumo doméstico de alumínio, em 2010, foi de $36,4 \%$ e, se consideradas somente as latas de alumínio, em 2011, a relação foi de 98,3\%. Para a Associação Brasileira de Celulose e Papel (Bracelpa, 2013), em 2011, o consumo aparente de papel no Brasil foi de 9,6 milhões de toneladas e a recuperação de aparas foi de 4,4 milhões de toneladas, representando uma taxa de recuperação de $46 \%$. No entanto, a Associação Brasileira do Papelão 
Ondulado (Abpo) aponta um índice de reciclagem de 75\% para o papel ondulado em 2010 (Abpo, 2010). A taxa de recuperação de plástico tipo politereftalato de etila (PET) foi de $57,1 \% \mathrm{em} 2011$, segundo dados da Associação Brasileira da Indústria de PET (Abipet, 2013) e o índice de reciclagem do vidro, de $49 \%$ em 2007, conforme a Associação Técnica Brasileira das Indústrias Automáticas de Vidro (Abividro, 2013). Com exceção do alumínio, os demais apresentam índices de recuperação baixos, mostrando o acerto da PNRS em incentivar as relações entre catadores e empresas para a recuperação de materiais pós-consumo.

Ao se levar em consideração os índices de reciclagem de material pós-consumo no Brasil, fica evidente a necessidade de estudos que analisem essas cadeias a fim de descrever quais são os atores envolvidos, quais os benefícios sociais, econômicos e ambientais oriundos da reciclagem, quais os fatores de sucesso que tornam o Brasil relevante no cenário internacional, de que maneira a recuperação de produtos e materiais está sendo viabilizada e operacionalizada, entre outras questões a serem exploradas.

Nos países desenvolvidos, a pesquisa em gestão de resíduos do consumo tem enfatizado as tecnologias relacionadas à coleta, ao transporte, ao armazenamento, ao reaproveitamento e à sua industrialização; já nos países em desenvolvimento, destaca-se a atuação dos catadores em detrimento dos estudos relativos à tecnologia (Gonçalves-Dias, 2009). Pode-se afirmar que a solução brasileira para o problema do resíduo pós-consumo fez uma opção preferencial às organizações de catadores, o que faz sentido como parte de uma política de inclusão social. No entanto, alguns autores mostram que os catadores brasileiros encontram-se fragilizados social e economicamente (Leal et al., 2003; Aquino et al., 2009; Gonçalves-Dias, 2009), e que suas organizações (cooperativas e associações) apresentam diversas barreiras técnicas e econômicas (Besen et al., 2006; Ribeiro e Besen, 2007; Gonçalves-Dias, 2009, GTZ, 2010). Com a PNRS, instituída pela Lei 12.305/2010, o governo brasileiro optou por políticas públicas na gestão de resíduos sólidos com inclusão dos catadores (Brasil, 2010), sendo relevantes, portanto, as abordagens de pesquisas na gestão de resíduos sólidos no Brasil que considerem a atuação desses catadores para que, realmente, sejam incluídos social e economicamente na cadeia de reciclagem no país.

As pesquisas de gestão de resíduos, sob a ótica empresarial, concentram-se no ambiente interno das organizações e na sua capacidade de implementar políticas de reutilização e reciclagem de resíduos; encontram-se lacunas na literatura nacional, no entanto, para estudos que tratem do papel dos catadores na cadeia de reciclagem (Gonçalves-Dias, 2009). Conforme dito anteriormente, Paula et al. (2010) também enfatizam o papel dos catadores para a consolidação de programas de logística reversa de empresas interessadas na recuperação de produtos e materiais.

\section{MÉTODO DE PESQUISA}

Essa pesquisa teve como objetivo geral analisar a inserção das organizações de catadores de materiais recicláveis na logística reversa de empresas, por meio da comercialização direta para reciclagem de embalagens pós-consumo, em diversos setores de embalagens (papelão, vidro, plástico e embalagem longa vida). Como objetivos específicos foram estabelecidos: descrever os programas empresariais de logística reversa com inclusão das organizações de catadores, considerando suas motivações, sob a perspectiva das empresas e das organizações; e identificar oportunidades e barreiras para o fortalecimento dessa relação nas práticas setoriais de logística reversa.

Para esta pesquisa, utilizou-se de método qualitativo de caráter exploratório. Entre as estratégias alternativas, relacionadas com as pesquisas qualitativas, Creswell (2010) cita os estudos de casos, nos quais o pesquisador explora profundamente programas, eventos, atividades e indivíduos. O estudo de caso investiga um fenômeno contemporâneo, em um contexto de vida real, em que os limites entre o fenômeno e o contexto não estão claramente definidos (Yin, 2010).

O objeto deste relato, baseia-se em casos múltiplos, tendo como foco o estudo das relações entre quatro cooperativas e quatro empresas compradoras de materiais recicláveis. Para seleção das

Revista de Gestão Social e Ambiental - RGSA, São Paulo, v. 7, n. 3, p. 20-36, out./dez., 2013. 
cooperativas de catadores, utilizou-se, como pré-requisito, sua integração às cadeias de suprimento reversas, considerando a atuação dessas como fornecedoras de primeira camada, conforme definição de Lambert et al. (1998). Foram selecionadas empresas produtoras dos setores de embalagens que compram diretamente de cooperativas de catadores (embalagem composta, aço, plástico PET, papelão e vidro). Desse levantamento, foi obtida uma listagem de sete empresas, três do setor de papelão, duas de vidro, uma de aço e uma de embalagem composta. Ao serem contatadas, obteve-se o consentimento de uma representante de cada setor, com exceção do setor de aço. Com base nesses critérios, as seguintes empresas e cooperativas de catadores foram selecionadas:

- Empresas: Suzano Papel e Celulose S/A (papelão), Tetra Pak Ltda. (embalagem longa vida), Unnafibras Têxtil Ltda. (plásticos PET) e Owens-Illinois do Brasil Indústria e Comércio S/A (vidro);

${ }^{\circ}$ Cooperativas: Cooperativa de Catadores Autônomos de Papel, Aparas e Materiais Reaproveitáveis - Coopamare; Cooperativa Regional de Coleta Seletiva e Reciclagem da Região Oeste - Cooperação; Cooperativa de Produção, Coleta, Triagem e Beneficiamento de Materiais Recicláveis da Miguel Yunes - Cooper Vira Lata e Coopermyre.

Convém ressaltar que a Coopermyre foi selecionada como explanação teórica rival, pois a cooperativa não realiza comercialização direta para empresas.

Como aponta Yin (2010), as unidades de análise são componentes especialmente importantes de um projeto de pesquisa baseado em estudo de caso. A unidade de análise, ainda conforme o autor, relaciona-se com a questão de pesquisa. Como o objetivo desse estudo foi analisar a inserção das cooperativas de catadores em práticas setoriais de logística reversa, adotou-se como unidade de análise, as relações comerciais empresas-cooperativas de catadores, conforme apresentadas na figura 1.

\begin{tabular}{|l|l|l|l|}
\hline \multicolumn{1}{|c|}{ Cooperativas } & & \\
Empresas & Coopamare & & \\
\hline Suzano & & $\mathrm{X}$ & $\mathrm{X}$ \\
\hline Tetra Pak & & $\mathrm{X}$ & $\mathrm{X}$ \\
\hline Owens-Illinois & & $\mathrm{X}$ & \\
\hline Unnafibras & & $\mathrm{X}$ & \\
\hline
\end{tabular}

Figura 1: Relações comerciais estudadas

Fonte: Elaborado pelos autores

As entrevistas foram realizadas com representantes das organizações, entre os meses de julho e dezembro de 2011. Na figura 2, estão listadas as funções dos entrevistados.

\begin{tabular}{|l|c|c|l|}
\hline Cooperativas de Catadores & \multicolumn{2}{|c|}{ Empresas } \\
\hline Coopamare & Presidente & Suzano & $\begin{array}{l}\text { Consultor externo responsável pelos } \\
\text { relacionamentos com as cooperativas }\end{array}$ \\
\hline Cooperação & Secretário & Owens-Illinois & Coordenador de sustentabilidade \\
\hline Vira Lata & $\begin{array}{c}\text { Coordenador de } \\
\text { Estoque }\end{array}$ & Unnafibras & Gerente de compras \\
\hline Coopermyre & Presidente & TetraPak & Especialista em desenvolvimento ambiental \\
\hline
\end{tabular}

Figura 2: Relação dos cargos dos entrevistados das organizações pesquisadas

Fonte: Elaborado pelos autores

Foram utilizadas múltiplas fontes de evidência para a coleta dos dados, tais como fontes primárias por meio de entrevistas semiestruturadas e focadas nos membros das organizações (empresas e organizações de catadores); e fontes secundárias, por meio do levantamento de dados, 
por meio de pesquisa bibliográfica, investigação documental e observação em campo, durante visitas técnicas.

Na pesquisa realizada por Aquino et al. (2009), sobre integrantes da cadeia reversa de pósconsumo da região da grande Florianópolis, foi proposta uma organização logística para as associações de catadores no sentido de facilitar a comercialização direta de seus produtos às indústrias recicladoras, visando à agregação de valor. Os autores embasaram-se nas categorias de análise utilizadas nesse estudo para elaboração dos roteiros das entrevistas conforme Figura 3.

\begin{tabular}{|l|c|c|}
\cline { 2 - 3 } \multicolumn{1}{l|}{} & $\begin{array}{l}\text { Cooperativas } \\
\text { de Catadores }\end{array}$ & Empresas \\
\hline $\begin{array}{l}\text { Área de atuação/ Abrangência; Atividades desenvolvidas; } \\
\text { dificuldades e limitações; forma de pagamento; forma de } \\
\text { transporte; materiais comercializados; preços praticados; } \\
\text { quantidade de material processada }\end{array}$ & $\mathrm{X}$ & $\mathrm{X}$ \\
\hline $\begin{array}{l}\text { Compradores; infraestrutura e equipamentos; número de } \\
\text { trabalhadores envolvidos }\end{array}$ & $\mathrm{X}$ & \\
\hline $\begin{array}{l}\text { Condições para realizar parcerias; exigências para } \\
\text { comercialização direta (qualidade e quantidade); produto final } \\
\text { comercializado }\end{array}$ & $\mathrm{X}$ \\
\hline
\end{tabular}

Figura 3: Categorias utilizadas para elaboração das entrevistas

Fonte: Aquino et al. (2009)

Para que se pudesse chegar à conclusões bem fundamentadas, fez-se necessário a triangulação dos dados (Yin, 2010). As organizações estudadas foram então analisadas isoladamente, com base nas categorias, tendo como suporte o software Atlas.ti. Depois foram comparados os dados obtidos entre as cooperativas de catadores e as empresas pela combinação de padrões, pelo cruzamento e pela sobreposição de dados, visando avaliar a integração das cooperativas de catadores em práticas de logística reversa.

\section{ANÁLISE E DISCUSSÃO DOS RESULTADOS}

A análise e a discussão dos resultados encontram-se a seguir detalhadas, de acordo com o seu setor.

\subsection{Setor de papelão}

No setor de papelão, as cooperativas de catadores Coopamare, Cooper Vira Lata e Cooperação comercializam com a empresa Suzano. Apenas a cooperativa Cooperação tem também relações comerciais com outra empresa produtora no setor de papel e celulose (Figura 4). Vale ressaltar que a cadeia de suprimentos da empresa Suzano é classificada como ciclo aberto, pois a embalagem de papelão adquirida é utilizada na produção de um produto específico, o papel Reciclato ${ }^{\circledR}$. Ou seja, um produto, portanto, distinto do original, que visa ao atendimento de um segmento específico do mercado devido ao conceito do produto, conforme explicam Carvalho e Barbieri (2010). Já a cadeia reversa, envolvendo a Coopermyre e aparistas, é considerada de ciclo fechado segundo esses autores, pois visa a fabricação de embalagens similares, caracterizando-se pela alta eficiência no fluxo reverso. 


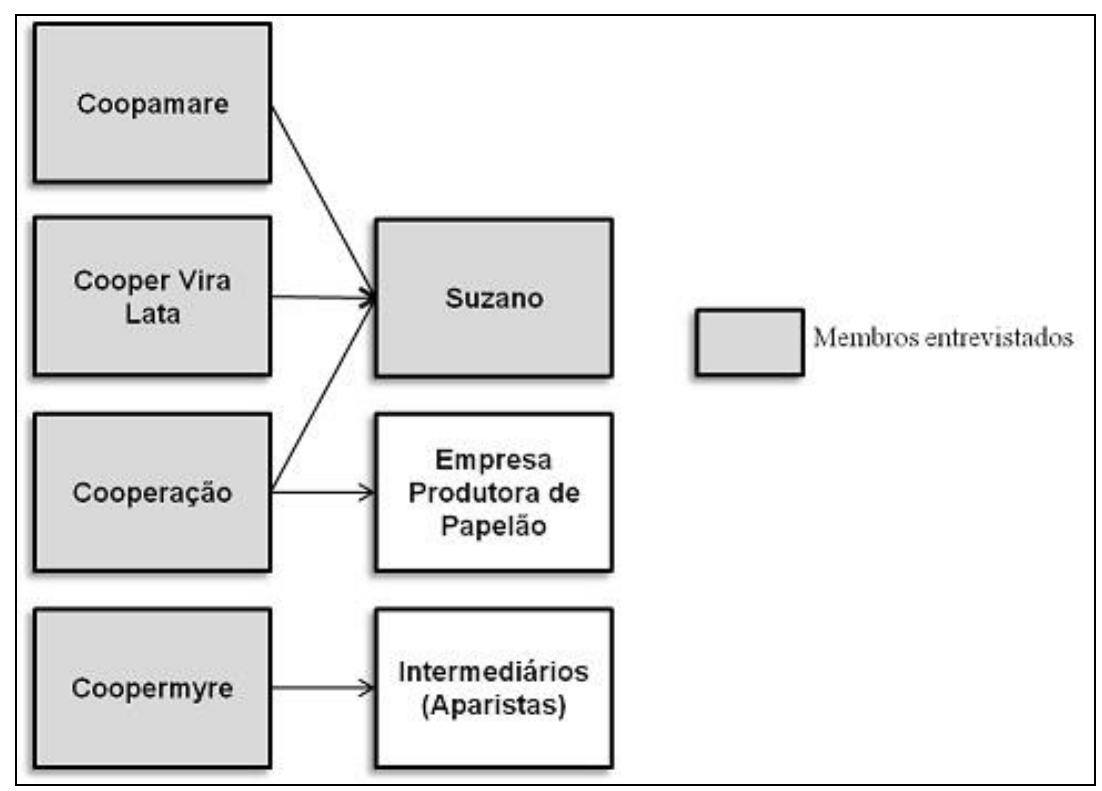

Figura 4: Relações entre cooperativas de catadores e empresas estudadas no setor de papelão Fonte: Elaborada pelos autores

A iniciativa de parceria foi da Suzano e ocorreu junto com o Banco Real, que se fundiu posteriormente ao Banco Santander, além do Instituto Ecofuturo - uma Organização da Sociedade Civil de Interesse Público, mantida pela Suzano, da Fundação Banco de Brasil e da Fundação Avina. O Banco Santander desempenhou papel importante para a inserção das cooperativas de catadores no mercado, pelo financiamento para capital de giro sem juros aplicáveis, em um programa que se iniciou em 2007. As fundações auxiliam no aporte e em capacitação gerencial, enquanto a OSCIP atua como gestora do programa.

A compra de papéis recicláveis de cooperativas de catadores é desfavorável economicamente em comparação à aquisição de aparistas. Sendo assim, a motivação da empresa para integração das cooperativas de catadores deve-se, principalmente, ao seu programa de responsabilidade socioambiental. Como esta prática está relacionada à produção do papel reciclado Reciclato®, ela repercute pelo seu ciclo de vida, envolvendo diversas áreas como a de Produto, Certificação, Compras, Institucional, Sustentabilidade e Infraestrutura. O Reciclato® é um papel para impressão e escritório $100 \%$ reciclado de acordo com a seguinte composição: aproximadamente $25 \%$ de papel reciclado pós-consumo e $75 \%$ material obtido na produção de papel de outras unidades industriais da empresa. Todas as cooperativas entrevistadas, com exceção da Coopermyre, afirmaram que a comercialização direta iniciou-se no setor de papelão. A primeira cooperativa a manter vínculos com a empresa foi a Coopamare, uma das pioneiras nas iniciativas de cooperativismo de catadores. O primeiro contato da empresa com a cooperativa ocorreu no ano de 1999, com interesse em adquirir os papéis recicláveis, Na época da pesquisa, a empresa possuía relações comerciais com cerca de 80 cooperativas de catadores situadas nos municípios da Região Metropolitana de São Paulo, Região do Grande ABC, Sorocaba e Região, Região Metropolitana de Campinas e município de São José dos Campos.

Quanto às relações estabelecidas entre as cooperativas de catadores e a Suzano, percebe-se que essa apresenta uma série de critérios no seu processo de seleção quanto às cooperativas, como a não-utilização de mão de obra infantil, ausência de conflitos com comunidade do entorno e de práticas de atividades ilícitas (ex.: mercado clandestino de vidro para falsificação de bebidas como uísques e licores de marcas famosas), entre outras. Tais exigências se devem aos critérios de homologação de fornecedores para obtenção de certificação florestal, a Forestry Stewardship Council (FSC), além da corresponsabilidade da empresa em relação às atividades desempenhadas pelas cooperativas. 
A Suzano também utiliza critérios de qualidade e localização para compra de materiais recicláveis de cooperativas de catadores. São incluídas, portanto, cooperativas que distam menos que 200 quilômetros das unidades fabris da empresa e que geram quantidade mínima entre 10 e 12 toneladas semanais de papéis recicláveis. Apesar das exigências quanto à qualidade do papelão reciclável, bem como questões de segurança no seu transporte, as operações realizadas pelas cooperativas são relativamente simples, exigindo a separação do papelão entre os materiais recicláveis e a confecção de fardos por meio de prensas.

Apesar de, inicialmente, a Suzano ter buscado o contato com as cooperativas para relações comerciais, no decorrer do tempo, as próprias cooperativas começaram a contatar a empresa devido à prática de preço justo, pois são utilizados valores de referência apresentados pela entidade do setor, a Bracelpa. Com base no relatório da cooperativa Cooperação, de novembro de 2011, comparando-se os valores praticados em $\mathrm{R} \$ / \mathrm{kg}$, verificou-se que no setor de papel e celulose, os preços praticados pelas empresas foram 12\% superior aos dos intermediários (aparistas). $\mathrm{O}$ representante da empresa repassa mensalmente informações quanto ao preço dos materiais recicláveis para endereços eletrônicos das cooperativas, fato que também foi mencionado pelo entrevistado de uma cooperativa.

A organização em rede de cooperativas de catadores, nas quais as cooperativas de menor escala transferem os materiais recicláveis para cooperativas maiores, facilita as operações e gera ganhos de escala, como no caso da cooperativa Cooperação. A Coopermyre, apesar de não vender diretamente para empresas produtoras, comercializa esporadicamente com uma empresa no setor de papelão. Essa empresa adquire papelão de outra cooperativa e, quando essa não possui volume suficiente para carregamento, a Coopermyre é contatada para verificar a disponibilidade de materiais recicláveis para venda, visando completar a carga.

O ganho de escala é função, principalmente, da demanda de mercado e foi obtido devido ao crescimento da busca por produtos sustentáveis, principalmente de clientes corporativos. Entretanto, no segmento de mercado de papéis reciclados para impressão e escritório, as vendas têm baixa representatividade na receita da Suzano, somente $2 \%$ do total. Já os volumes gerados de papelão recicláveis são consideráveis, pois as embalagens de papelão são amplamente utilizadas em operações logísticas para o transporte de produtos, podendo ser considerada uma medida do "motor da economia". Ainda com base no relatório da cooperativa Cooperação, o papelão representa mais de $60 \%$ do volume, em quilograma e, aproximadamente, $40 \%$ em receita em relação aos materiais recicláveis comercializados.

As barreiras para comercialização direta para a cooperativa Coopermyre devem-se aos conflitos entre prazo de pagamento e remuneração dos cooperados, envolvendo, portanto, questões administrativas. Para as cooperativas que vendem para as empresas, foram citadas as variações de preço, a redução de volume de venda devido à existência de cotas de compra, e diversificação de comprador no período entre os meses de dezembro e janeiro.

\subsection{Setor de vidro}

As relações entre as cooperativas que atuam como fornecedoras de primeira camada para as empresas analisadas podem ser visualizadas na Figura 5. Dados da Abividro revelam taxa de reciclagem de $49 \%$ no Brasil, no ano de 2007 . No entanto, se deve considerar que $45 \%$ da produção compõem as embalagens retornáveis que podem ser reenvasadas - cerca de 30 a 40 vezes, antes do fim da sua vida útil, como informou o representante da Owens-Illinois. Ressalta-se aqui a existência de dois subsistemas reversos: a do reuso, visando recuperação de produtos e extensão de sua vida útil; e da reciclagem, pela recuperação dos materiais. Entretanto, as cooperativas de catadores não atuam no canal reverso de reuso. 


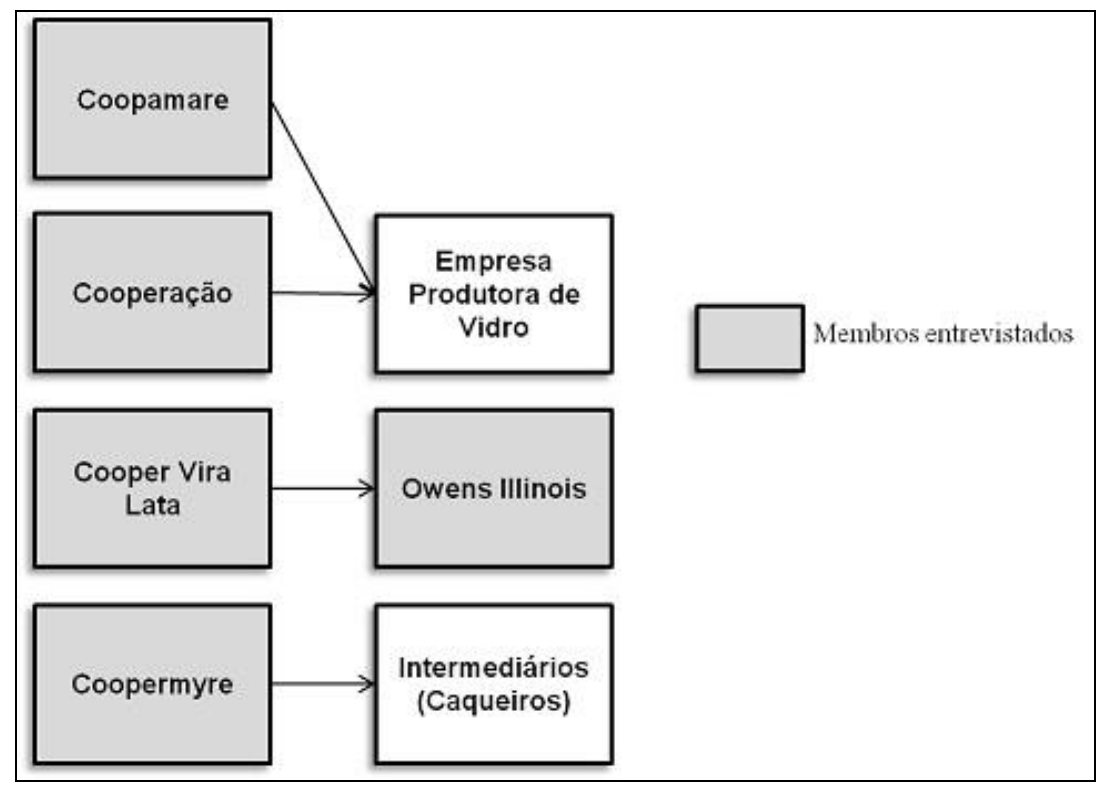

Figura 5: Relações entre cooperativas de catadores e empresas estudadas no setor de vidro. Fonte: Elaborada pelos autores

Ao cruzar os dados das entrevistas, observou-se que as exigências de qualidade por parte das empresas do setor provocaram o desenvolvimento de atividades pelas cooperativas visando agregação de valor aos materiais recicláveis. Essas atividades são basicamente separação por cor (verde, branco, âmbar e misto), limpeza para retiradas de metais e granulação, seja pela quebra com marretas, seja pela sua trituração, processos fundamentais para a eficiência da cadeia logística do vidro. Os investimentos em fornos para produção de vidro são muito elevados e, portanto, o controle de qualidade dos vidros recicláveis deve reduzir os riscos de danos dos equipamentos. Soma-se o fato dos vidros recicláveis serem destinados, juntamente com a matéria-prima original, para sua substituição. A presença de impurezas nos materiais recicláveis pode representar riscos de contaminação de lotes inteiros de produção.

Após a execução das etapas de pré-processamento pelas cooperativas Cooperação e Coopamare, para a reintrodução dos cacos de vidros pela empresa, torna-se necessária, ainda, a realização da etapa de beneficiamento. Como a atividade é terceirizada, pode ser realizada pelos fornecedores ou pela própria empresa. A necessidade de beneficiamento é considerada na precificação dos vidros recicláveis. Assim, uma forma de agregar valor por parte da cooperativa seria o beneficiamento dos cacos, processo esse realizado pela Cooper Vira Lata.

A Coopermyre já realizou vendas de vidros recicláveis para empresas produtoras, entretanto, devido às exigências de pré-processamento e em razão das dificuldades quanto à acumulação de volume nas caçambas no prazo estipulado, há preferência de comercialização para intermediários, os caqueiros. O acúmulo de volume de vidro, pela Coopamare e Cooper Vira Lata, deve-se à realização de coleta na fonte geradora. Como a coleta por catadores ("carrinheiros") é a principal fonte de materiais recicláveis da Coopamare, os seus associados podem realizar uma triagem no momento da coleta. Já para a Cooper Vira Lata, a segregação na fonte foi viabilizada por meio de parceria com outras empresas na cadeia de reciclagem.

Constatou-se que a empresa exige somente a separação por cor. No entanto, a Coopamare realiza a sua quebra para melhor aproveitamento da capacidade das caçambas que são dispostas nas cooperativas por essa empresa. Ocorre acúmulo de volume de entrada de vidro reciclável devido à falta de recursos humanos (cooperados) para pré-processamento. Já na Cooper Vira Lata ocorre acúmulo de volume de cacos de vidro obtidos com auxílio de trituradores. A Coopamare relatou que não se adaptou quanto à utilização desses equipamentos, devido ao ruído provocado. Um aspecto importante da atividade de logística, conforme se encontra na literatura convencional sobre esse tema, refere-se à localização dos estabelecimentos e, como consequência, às distâncias de saída e 
entrada de material. Ao se analisar essas cooperativas percebem-se desvantagens quanto à localização da Coopamare. Essa realiza suas atividades sob um viaduto localizado em área residencial, enquanto a Cooper Vira Lata está localizada em um galpão, distante de residências, o que favorece o uso de níveis mais altos de ruído provocado pelos equipamentos.

Deve-se ressaltar que o principal material reciclável vendido pela Cooper Vira Lata é o vidro devido à parceria existente entre ela, a empresa de bebidas Diageo, a empresa produtora de vidro Owens-Illinois e estabelecimentos comerciais, tais como casas noturnas, bares e restaurantes. Nesse caso, como ocorre envolvimento de outros membros da cadeia de suprimentos para a logística reversa, o controle de quantidade e qualidade é facilitado pelo rastreamento das embalagens com a coleta realizada na fonte geradora de resíduos sólidos. Esse projeto, conhecido como "Glass is Good", foi criado em 2010 e consiste na coleta de vidros, pela cooperativa, nos estabelecimentos, visando sua separação por cor, trituração e comercialização à Owens-Illinois. Nesse caso específico, a cadeia reversa é fechada, pois ocorre coleta diretamente na fonte geradora com controle da sua origem.

A empresa Diageo controla o fluxo de informações entre os membros, visando a eficiência operacional, como questões de roteirização realizada pela cooperativa. Foi formalizado um convênio entre os membros da cadeia, incluindo-se a Cooper Vira Lata. As relações entre a empresa e a cooperativa extrapolam o ambiente das negociações de compra, integrando-se em um contexto mais amplo. Devido ao sucesso da parceria e cumprimento de metas, a cooperativa recebeu um veículo próprio (van Ducatto) para coleta dos vidros recicláveis nos bairros da cidade. Foram citadas ainda, pelos entrevistados, a realização de reuniões, visitas e comunicações por meio de rádios.

A área de Sustentabilidade da Owens-Illinois realiza a avaliação de performance dos fornecedores, incluindo a cooperativa parceira, por meio de um controle mensal de fornecimento. Foi ressaltada a relevância desse contato pós-negociações para monitoramento do desempenho. Entre os critérios considerados estão o desenvolvimento e crescimento, metas de qualidade, exigências de qualidade, além de regularização legal. Foram reforçadas as exigências da indústria quanto à qualidade e às especificações a serem atendidas, tais como a ausência de pedras, tampas ou rótulos metálicos, impurezas metálicas, plásticas e madeira, considerando-se os possíveis prejuízos na produção, como contaminações de lotes ou danos nos equipamentos, como nas paredes refratárias do forno.

A Diageo não atua diretamente nos fluxos físicos reversos, mas sim como intermediária nos fluxos reversos de informações. Por meio dos fluxos de informações, a empresa tem uma visão holística da cadeia de suprimentos, visando uma gestão eficiente dos fluxos entre os membros da cadeia de suprimentos e suas operações. Quanto ao aspecto econômico, os preços dos cacos de vidro são superiores aos das matérias-primas virgens. As motivações para estruturação da logística reversa no setor de vidros estão, então, relacionadas com a existência de mercado clandestino e, por conseguinte, com a imagem corporativa. Essa preocupação quanto à corresponsabilidade com a destinação para fins ilícitos também foi apresentada pelo representante da cooperativa Cooperação.

Dados sobre preços de vidros recicláveis, repassados pelas cooperativas, mostram a agregação de valor com a realização do seu pré-processamento. Em geral, a comercialização de vidro diretamente para empresas representa um incremento entre 40 e $60 \%$ em relação aos preços praticados por intermediários. Para a Cooper Vira Lata, os preços dos vidros recicláveis representam um incremento de $75 \%$. A precificação é decorrente da necessidade de beneficiamento e da distância do fornecedor. Somente a cooperativa Cooper Vira Lata afirmou que o vidro é o único material reciclável que não sofre oscilação de preços durante o ano, mostrando a importância da parceria para evitar grandes oscilações já que os materiais recicláveis comportam-se como commodities.

A Owens-Illinois garante a compra de todo material reciclável da cooperativa, uma vez que o volume não é um fator limitante para a empresa. A quantidade de material reciclável disponível 
no mercado ainda é pequena para suprir a sua demanda. $\mathrm{Na}$ Cooper Vira Lata são retirados cacos de vidro semanalmente, atingindo cerca de 70 toneladas por mês.

O prazo de pagamento realizado pela empresa de vidro exigiu da Coopamare um planejamento das operações para não prejudicar a distribuição das sobras entre os cooperados. As cooperativas distribuem aos seus cooperados o superávit entre as receitas e as despesas do exercício e estabelecem, como procedimento interno, que a realização da comercialização do vidro com a empresa aconteça sempre no dia 20 de cada mês, no máximo, até o dia 25 , para viabilizar a remuneração dos cooperados até o dia 10 do mês seguinte.

\subsection{Setor de plásticos PET}

Nesse setor, todas as quatro cooperativas apontaram dificuldades enfrentadas para o acúmulo de volumes devido à grande variedade de plásticos existente e a necessidade de separá-los por tipo de molécula para efeito de aproveitamento na cadeia reversa. No caso do PET, entretanto, existem iniciativas de venda direta das cooperativas para as empresas recicladoras. As relações comerciais estudadas podem ser visualizadas na Figura 6.

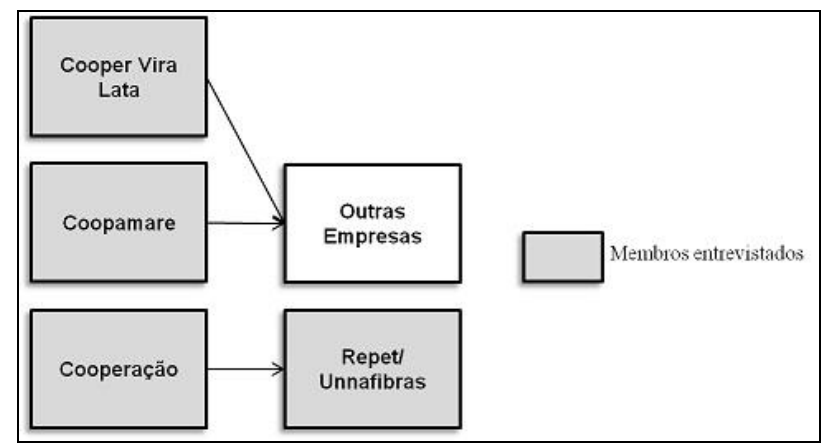

Figura 6: Relações entre cooperativas de catadores e empresas no setor de plásticos PET Fonte: Elaborada pelos autores

Os plásticos PET são destinados para novas cadeias, distintas da original, transformando o produto logístico de embalagem para produtos com diversas aplicações, com destaque para fibras de poliéster com aplicações em tecidos, no caso da empresa entrevistada. Por isso, as cadeias reversas no setor de PET são consideradas de ciclos abertos. Segundo a Abipet (2013), as cooperativas de catadores representam $21 \%$ do volume retornado, enquanto os catadores avulsos somam $47 \%$.

A empresa Unnafibras Têxtil Ltda., criada em 1996, utiliza-se de plásticos PET como matéria-prima para a fabricação de fibras de poliéster. A Unnafibras teve início a partir de uma desassociação do grupo Rhodia, objetivando a produção de um produto reciclado competitivo diferenciado, não uma commoditie. Em 1996, foi implantada uma unidade de processamento de garrafas Repet Reciclagem de Termoplásticos Ltda. (PET), em Mauá - SP, pelo grupo, tendo em vista o fornecimento de PET granulado para a Unnafibras. A Repet revaloriza as garrafas de PET e o polímero, produzido sob a forma de flakes e granulados, é transformado em fibras têxteis pela Unnafibras Têxtil, localizada em Santo André - SP.

As cooperativas de catadores representam menos de $4 \%$ do volume de plásticos recicláveis adquiridos pela Repet. Atualmente, quinze cooperativas do Estado de São Paulo fornecem plástico PET para a empresa, cuja compra de materiais recicláveis iniciou-se em 2004. A distância entre a unidade operacional e as cooperativas, para comercialização direta, é de até $40 \mathrm{~km}$. A negociação com as cooperativas é facilitada com as que apresentam boa gestão na condução das suas operações, além de estrutura favorável, como localização, logística do galpão e equipamentos cedidos pela Prefeitura. Além disso, o volume e a capacidade de prensagem são fundamentais devido aos custos do frete.

A Unnafibras Têxtil realiza visitas aos fornecedores, inclusive nas cooperativas, para avaliações de qualidade, produtividade e layout. Realiza também visitas guiadas na sua unidade 
operacional para cooperativas, visando alcançar uma convergência entre o pensamento industrial e as formas de organização das cooperativas, além de sensibilizar os catadores da importância do papel que eles desempenham na cadeia da reciclagem. Iniciativas como estas de visitas de cooperativas à empresa já foram realizadas pela associação civil Central de Cooperativas e Empreendimentos Solidários (Unisol) Brasil e pela Oscip Instituto GEA - Ética e Meio Ambiente.

Para a compra das garrafas PET exige-se um alto padrão de qualidade no que se refere à ausência de contaminação, como, por exemplo, restos de produtos, lacres e colas. Os materiais recicláveis adquiridos sem intermediação, com a organização responsável pelo enfardamento, como as cooperativas de catadores, garantem melhor qualidade já que as relações comerciais ocorrem diretamente com os responsáveis pela triagem, além de evitar exposição excessiva dos plásticos, transferências de depósitos e incorporação de impurezas. A empresa considera que as cooperativas se destacam no desempenho das atividades de classificação dos plásticos.

Os plásticos compõem-se de uma ampla variedade de polímeros, o que torna a triagem trabalhosa, além do seu processamento não permitir a mistura de diferentes moléculas no lote a ser processado devido aos riscos de contaminação da massa de materiais. A Cooper Vira Lata, que também comercializa plástico PET para as empresas, relatou o desenvolvimento de competências internas quanto à seleção dos plásticos por uma cooperada por meio da aprendizagem prática, utilizando-se de técnicas visuais, reação ao calor, entre outras.

Relatos da Repet indicam que atualmente a demanda por plástico PET reciclável é maior do que a oferta. O desequilíbrio entre oferta e demanda e a diversidade de plásticos existentes (efeito volume-variedade) exigem da empresa diversificação de canais de suprimentos, visando atingir os volumes necessários para a escala de produção. Como a reciclagem é atividade central da Unnafibras Têxtil, além das questões sociais e ambientais, o aspecto econômico é essencial para a viabilidade e competitividade do negócio.

O setor de plásticos, apesar do volume pouco representativo devido aos diversos tipos de plásticos existentes, possui os maiores valores de mercado, variando entre $R \$ 1,00$ e $R \$ 1,80$, em razão da sua classificação. Os valores referentes ao papelão, vidro e longa vida variam entre $\mathrm{R} \$ 0,30, \mathrm{R} \$ 0,15$ (sem beneficiamento) e $\mathrm{R} \$ 0,25$, respectivamente. Entretanto, como as empresas recicladoras não estão associadas às marcas, tais como as multinacionais produtoras de papel e vidro, as cooperativas de catadores apresentaram dificuldades na discriminação entre intermediários mal-intencionados e empresas recicladoras, acarretando em desafios quanto ao desenvolvimento de compradores.

\subsection{Setor de embalagem Longa Vida}

Somente as cooperativas Cooperação e Vira Lata comercializam embalagem Longa Vida por meio da empresa Tetra Pak, que coordena a atividade de coleta seletiva realizada pelas cooperativas. Na Figura 7 estão representadas as relações comerciais analisadas. A Tetra Pak possui relacionamento com cerca de 900 cooperativas localizadas em diversos estados brasileiros. $\mathrm{Na}$ empresa, a responsável pelo programa é a área de Meio Ambiente e a comunicação da empresa com as cooperativas é realizada por prestadores de serviço locais. A empresa atua como elo entre empresas recicladoras e cooperativas de catadores, não comercializa diretamente com essas. A Tetra Pak apresentou, em 2011, uma taxa de reciclagem entre 26 e $27 \%$. 


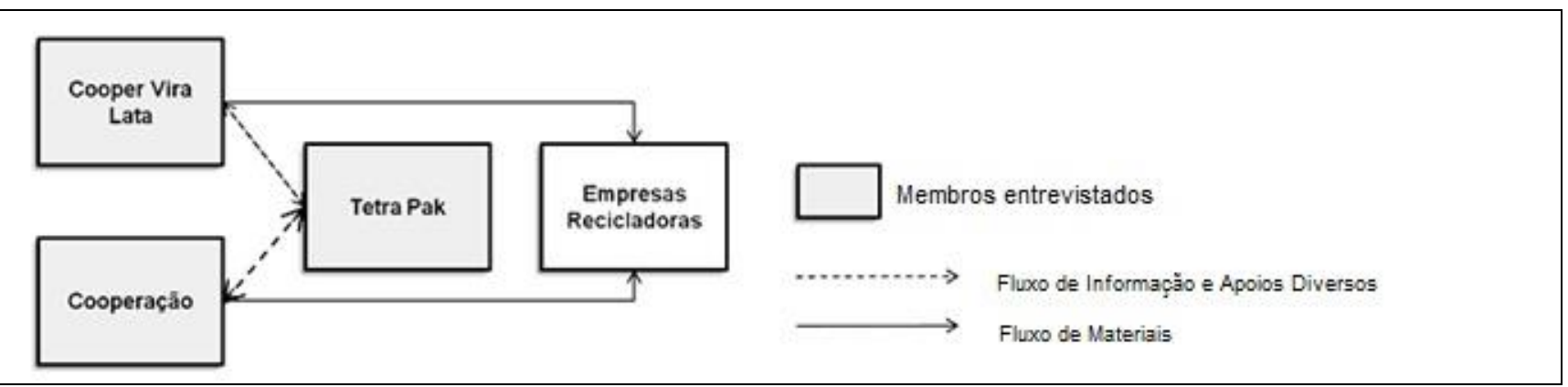

Figura 7: Relações entre cooperativas e empresas no setor de embalagem longa vida Fonte: Elaborada pelos autores

A embalagem longa vida é composta, tendo exigido investimentos em tecnologias apropriadas para separação dos materiais constituintes. Merece destaque o "Projeto Plasma" desenvolvido em parceria com as empresas Gerdau, Klabin e TSL Ambiental, visando a desagregação do composto plástico/alumínio, transformando-o em parafina e lingote de alumínio.

No caso das embalagens longa vida, foram perceptíveis as motivações referentes à competitividade por meio da agregação de valor, proporcionada por incrementos nas taxas de reciclagem e de responsabilidade social, por meio do reconhecimento do trabalho realizado pelos catadores. São disseminados os fluxos de informações da empresa para as cooperativas de catadores, por meio de folhetos explicativos, com o objetivo de ampliar a divulgação sobre a atuação dessas cooperativas na cadeia de reciclagem. A empresa considera que os folhetos explicativos, destinados às cooperativas de catadores, agregam valor para elas. No entanto, nas cooperativas de catadores estudadas não houve relatos quanto à percepção desse valor.

A empresa também elaborou um sistema de informações geográficas virtual, com buscador automático de pontos de coleta de embalagens longa vida disponível para toda sociedade, como as cooperativas de catadores. A Tetra Pak também já apresentou iniciativas para estimular ações públicas, provenientes de Prefeituras, quanto aos investimentos em infraestrutura nas cooperativas de catadores, como contrapartida. Importante destacar os esforços conjuntos com outras empresas, inclusive não fornecedoras da Tetra Pak, para implementação de projetos colaborativos para a reciclagem de embalagem longa vida.

O preço das embalagens cartonadas recicláveis é fixado pelas recicladoras e a precificação pode variar em razão do frete. Quando as cooperativas não realizam o transporte do material reciclável, as empresas descontam o frete do valor dos materiais recicláveis. Existem empresas recicladoras que exigem das cooperativas de catadores a entrega do material reciclável na empresa. Quanto ao transporte, é importante ressaltar que, nos casos estudados (incluindo dos outros setores), foi apontada, de forma unânime, a necessidade da empresa compradora responsabilizar-se pela logística dos materiais recicláveis entre as cooperativas e as empresas.

Para estimular e apoiar a comercialização entre cooperativas de catadores e empresas, a Tetra Pak realiza capacitação técnica e operacional em cooperativas de catadores por meio de consultores, incluindo aspectos referentes à manipulação, enfardamento e limpeza das embalagens longa vida e repasse de dados sobre a embalagem e sua reciclagem para evitar contaminação com outros materiais recicláveis, além de padrões de qualidade necessários (tipo e tamanho de fardos, por exemplo). Uma parceria estabelecida com o Compromisso Empresarial para Reciclagem (Cempre), associação sem fins lucrativos dedicada à promoção da reciclagem dentro do conceito de gerenciamento integrado do lixo, na qual a Tetra Pak é integrante, vem permitindo intensificar a capacitação profissional das cooperativas de catadores focada no processo produtivo, tendo em vista o crescimento e a eficiência contínuos. A empresa promove empréstimos de equipamentos, como prensas, para as cooperativas que ela mantém relacionamentos mais frequentes, como é o caso da cooperativa Cooperação que recebe doações de EPI da empresa Tetra Pak.

\section{CONSIDERAÇÕES FINAIS}

Revista de Gestão Social e Ambiental - RGSA, São Paulo, v. 7, n. 3, p. 20-36, out./dez., 2013. 
A pesquisa objetivou compreender a inserção de organizações de catadores em programas empresariais de logística reversa para reciclagem de embalagens pós-consumo. A análise das relações comerciais entre cooperativas de catadores e empresas permitiu o entendimento da atuação das cooperativas de catadores na logística reversa de empresas, a estruturação de canais reversos pelas empresas, além de explorar cenários em diversos setores de embalagens: vidro, papelão, embalagem longa vida e plástico PET.

Como resultado, essa pesquisa mostrou que a inserção das cooperativas de catadores, estudadas em programas empresariais de logística reversa, é decorrente das motivações empresariais, sejam elas de responsabilidade socioambiental, compras, incremento de taxa de reciclagem para competitividade da embalagem ou de recuperação de materiais. Mostrou ainda que as motivações definem a estruturação de canais reversos pelas empresas, influenciando nas exigências às cooperativas de catadores e na quantidade de cooperativas de catadores integradas em seus programas.

A análise das relações entre cooperativas de catadores e empresas permitiu a identificação de barreiras e oportunidades nas práticas setoriais de logística reversa. No setor do papelão, que apresenta bastante representatividade em volume de materiais recicláveis para as cooperativas e, consequentemente, em receitas, constatou-se que a dificuldade para integração de cooperativas de catadores é o planejamento e controle das suas operações, visando conciliar prazo de pagamento com o rateio das sobras entre cooperados.

No setor de vidro, as limitações da integração das cooperativas de catadores nas práticas de logística reversa encontram-se, principalmente, na obtenção de volume e no âmbito das operações. As exigências quanto ao pré-processamento dos vidros recicláveis contribuem para o desenvolvimento de processos nas cooperativas e agregam valor à atuação dessas nas cadeias reversas das embalagens de vidros.

O setor de plásticos apresentou-se como potencial para ser explorado pelas cooperativas de catadores, considerando-se suas competências e os preços dos plásticos recicláveis. A principal barreira encontrada foi a dificuldade das cooperativas no desenvolvimento de compradores. Nesse âmbito, sugere que as empresas focais das cadeias de plásticos, no caso as empresas de bens de consumo, possam desempenhar um papel importante, por meio do controle do fluxo de informações entre os membros, visando a integração dos processos de negócios.

A fragilidade e vulnerabilidade das cooperativas de catadores, um aspecto sempre lembrado na literatura sobre este tema, tendem a se reduzir quando elas se inserem na cadeia de suprimento de grandes empresas como fornecedoras de materiais recicláveis. Porém, elas continuam sendo o elo mais fraco dessas cadeias, em grande parte pela escala reduzida das suas operações e outros condicionantes familiares a qualquer pequeno fornecedor de uma grande empresa, tais como falta de capital de giro, localização, capacidade gerencial, formação do pessoal, entre outros. Percebeu-se que, apesar das cooperativas estudadas atuarem nos canais reversos como fornecedoras, sua representatividade é pequena em relação ao volume de materiais recicláveis processado pelas empresas. É importante salientar que a atuação das organizações de catadores terá novos direcionamentos com a efetivação da PNRS, que estava em fase de implementação no período da pesquisa. Recomenda-se, então, analisar os impactos dessa política nos processos de integração das cooperativas nas cadeias de reciclagem.

Verificou-se que, nos casos estudados, as barreiras existentes para as cooperativas de catadores relatadas na literatura (Besen et al., 2006; Ribeiro e Besen, 2007; Gonçalves-Dias, 2009), tais como falta de capital de giro, capacitação gerencial, recursos materiais, etc. foram contornadas com apoio de bancos, da Prefeitura, das organizações civis, ou da própria empresa compradora. Pesquisas que explorem a compreensão de como essa rede de apoio tem contribuído para o desenvolvimento das cooperativas de catadores seriam interessantes visando uma delimitação mais clara de meios de auxílio, de forma maximizar os benefícios e evitar sobreposição de papéis.

A maioria dos programas empresariais extrapola o limite geográfico dos municípios, mas existem restrições de distância em relação às unidades fabris. Tal limitação geográfica deve-se ao 
fato de que todas as empresas compradoras estudadas são responsáveis pelo transporte dos materiais recicláveis. Em umas das cooperativas estudadas, a localização em bairro residencial representou um fator limitante para utilização de equipamentos. Estudos que explorem a localidade das cooperativas permitiriam melhor compreensão da atual malha de atuação das cooperativas de catadores e, assim, forneceriam subsídios para sua integração.

Nesta pesquisa, a comercialização direta auxiliou no fortalecimento e desenvolvimento das organizações de catadores pelo planejamento de operações, visando a melhor distribuição de sobras aos cooperados, e do desenvolvimento de atividades para garantir melhor qualidade dos materiais recicláveis. Alguns autores afirmam que as relações com empresas promovem as cooperativas de catadores (Mota, 2005; Torres, 2008; GTZ, 2010; Sousa et al., 2012). Essa pesquisa contribui ao aprofundar de que maneira os vínculos com as empresas têm permitido o desenvolvimento das organizações de catadores e seu avanço na cadeia de reciclagem.

Existem desafios quanto aos fluxos de informações entre empresas e cooperativas de catadores, considerando-se as diferenças existentes quanto às suas formas de organização, às percepções dos valores agregados para ambas as organizações e à detenção de informações. A descentralização das cooperativas de catadores representa uma barreira quanto à similaridade nos fluxos de informações entre elas e as empresas. Os pesquisadores sugerem que a organização em rede de cooperativas de catadores, além de viabilizar a comercialização direta entre cooperativas de catadores e empresas, conforme relatado por cooperativas e empresas, pode representar uma oportunidade de gestão das informações para as cooperativas de catadores, garantindo sua uniformidade, a transferência e o reuso de experiências e conhecimentos; uma disseminação das melhores práticas.

Um aspecto que não foi tratado nessa pesquisa, mas fica como uma recomendação para futuros trabalhos refere-se aos relacionamentos internos entre cooperados e entre estes e seus dirigentes. Algumas falas ouvidas pelos entrevistados indicam a existência de questões referentes à falta de engajamento e estímulo de cooperados devido à elevada rotatividade e ao abandono de cooperados, tanto que foram contratados funcionários para os cargos que exigem estabilidade, como segurança e motoristas. A colaboração interna nas cooperativas possibilitou iniciativas de projetos, avanços na independência e autonomia e escala para comercialização com empresas. Quanto à temática de gestão de recursos humanos, ressaltam-se as lacunas existentes em relação às pesquisas sobre o papel da liderança nas cooperativas de catadores, bem como sobre os processos de escolhas dos dirigentes.

Também foram percebidas influências das organizações apoiadoras (ONGs, prefeituras, associações de classe, movimentos sociais, etc) nas formas das cooperativas organizarem-se e desempenharem seus trabalhos e atividades. Pesquisas que explorem essas influências poderiam trazer novas compreensões sobre as cooperativas de catadores, pois elas ainda continuam sendo pouco conhecidas enquanto elos de cadeias de suprimento, apesar de um discurso recorrente que as consideram parceiras fundamentais das políticas de sustentabilidade.

\section{REFERÊNCIAS}

Abal - Associação Brasileira de Alumínio (2013) Relação entre sucata recuperada e consumo doméstico. Recuperado em: 7 jul. 2013, de: http://www.abal.org.br/estatísticas /nacionais/reciclagem/total-aluminio/.

Abipet - Associação Brasileira da Indústria de Pet (2013). Censo da Reciclagem de PET no Brasil, 8. Recuperado em: 7 jul.2013, de: http://www.abipet.org.br/indexAjax.html? method=baixarArquivo\&id=377.

Abividro - Associação Técnica Brasileira das Indústrias Automáticas de Vidro (2013). Reciclagem no Brasil - Infográfico. Recuperado em: 7 jul.2013, de: http://www. abividro.org.br/reciclagemabividro/reciclagem-no-brasil. 
Abpo - Associação Brasileira do Papelão Ondulado (2010) Caderno ABPO - O papel. Recuperado em: 7 jul. 2010, de: http://www.abpo.org.br/artigos_presidente/presidente_dezembro_2010.pdf., dez.

Abrelpe - Associação Brasileira de Empresas de Limpeza Pública e Resíduos Especiais (2010) Panorama dos Resíduos Sólidos no Brasil 2010. 199 p.

Aquino, I. F., Castilho Jr. A. B., Pires, T. S. L (2009). A organização em rede dos catadores de materiais recicláveis na cadeia produtiva reversa de pós-consumo da região da grande Florianópolis: uma alternativa de agregação de valor. Gestão \& Produção, São Carlos, 16, (1).

Besen, G. R., Demajorovic, J., Ribeiro, H., Gunther, W. R. (2006) Programas municipais de coleta seletiva em parceria com organizações de catadores na Região Metropolitana de São Paulo sustentabilidade socioeconômica, sanitária e ambiental. In: Encontro da Anppas, 3. Brasília, DF, mar.

Bid - Banco Interamericano de Desenvolvimento (2010) Dinámicas de Organización de los recicladores informales - Tres casos de estudio en América Latina. Nota Técnica, (117). 65 p.

Bracelpa - Associação Brasileira de Celulose e Papel (2013) Evolução do consumo brasileiro de aparas. Recuperado em: 7 jul.2013, de: http://www.bracelpa.org.br/bra2/? q=node/141.

Brasil (2011) Ministério do Meio Ambiente (MMA) Plano Nacional de Resíduos Sólidos - versão preliminar para consulta pública. Brasília. 137p.

Brasil(2010) Lei 12.305. Institui a Política Nacional de Resíduos Sólidos; altera a Lei 9.605/1998; e dá outras providências.

Bunchaft, A. (2007) Recolección de materiales reciclables por parte de los recolectores: estrategia de sobrevivencia ante la pobreza urbana existente en Brasil. In: Gallina, A. et al. Innovaciones creativas y desarrollo humano. Montevideu: Editora Trilce. 319 p.

Carvalho, A., Barbieri, J.C.(2010) Sustentabilidade e gestão da cadeia de suprimento: conceitos e exemplos. In: Vilela Junior, A., Demajorovic (Orgs.) Modelos e ferramentas de gestão ambiental: desafios e perspectivas para as organizações. São Paulo: Editira Senac, (2 ${ }^{\mathrm{a}}$ ed.)

Cempre - Compromisso Empresarial para Reciclagem (2013) Política Nacional de Resíduos Sólidos - Agora é lei. Recuperado em: 7 jul.2013, de: http://www.cempre.org.br/ download/ pnrs_002.pdf.

Creswell, J. W. (2010) Projeto de pesquisa: métodos qualitativo, quantitativo e misto. (3.ed.) Porto Alegre: Artmed. 296p.

Demajorovic, J., Migliano, J. (2013) Política Nacional de Resíduos Sólidos e suas implicações na cadeia da logística reversa de microcomputadores no Brasil. Gestão \& Regionalidade, 29(87), 6480 , set/dez.

Dowlatshahi, S. (2010) A cost-benefit analysis for the design and implementation of reverse logistics systems: case studies approach. International Journal of Production Research, 48(5), 1361-1380.

Gonçalves-Dias, S. L. F. (2009) Catadores - Uma perspectiva se sua inserção no campo da indústria de reciclagem. São Paulo: Programa de Pós-Graduação em Ciência Ambiental, Universidade de São Paulo. 298p. Tese (Doutorado).

GTZ - Deutsche Gessellschaft fur Technische Zusammenarbeit. (2010) Partnerships for Recycling Management. The waste experts: enabling conditions for informal sector integration in solid waste management. Lessons learned from Brazil, Egypt and India. Eschborn. 31 p.

Hicks, C., Heidrich, O., Mcgovern, T., Donnelly, T. (2004) A functional model of supply chains and waste. International Journal of Production Economics, 89(2), 165-174, maio. 
Instituto Ethos. (2007) Vínculos de negócios sustentáveis em resíduos sólidos. Recuperado em: 25 fev.2013, de: http://www3.ethos.org.br/wp-content/uploads/2012/12/04_.

Jayaraman, V., Guide, V. D. R., Srivastava, R. (1999) A closed-loop logistics model for remanufacturing. Journal of the Operational Research Society, 50(5), 497-508.

Lambert, D. M., Cooper, M. C., Pagh, J. D. (1998) Supply Chain Management: Implementation Issues and Research Opportunities. The International Journal of Logistics Management, 9(2), 1-20.

Leal, A. C., Gonçalves, M. A., Thomaz JR. A. (2003) A reinserção do lixo na sociedade do capital: uma contribuição ao entendimento do trabalho na catação e na reciclagem. Revista Terra Livre, 18(19), 177-190.

Medina, M. (2000) Scavenger cooperatives in Asia and Latin America. Resources, Conservation and Recycling, 31, 51-69.

Mota, A. V. (2005, jun/jul.) Do lixo à cidadania. Revista Democracia Viva, (27), Rio de Janeiro.

MTE - Ministério do Trabalho e Emprego. (2002) Classificação Brasileira de Ocupações: CBO/2002. Brasília: MTE.

Nakashima, K., Arimitsu, H., Nose, T., Kuriyama, S., Environmental, U. S., Agency, P. (2002) Analysis of a product recovery system. International Journal of Production Research, 40(15), 3849-3857.

Paula, M. B., Souza-Pinto, H., Souza, M. T. S. (2010) A importância das cooperativas de reciclagem na consolidação dos canais reversos de resíduos sólidos urbanos pós-consumo. In: Simpósio de Administração da Produção, Logística e Operações Internacionais. Anais, 1-16.

Pereira, M. C. G., Teixeira, M. A. C. (2011) A inclusão de catadores em programas de coleta seletiva. Cadernos Ebape, 9(3), 895-913.

Ribeiro, H., Besen, G. R. (2007) Panorama da coleta seletiva no Brasil: desafios e perspectivas a partir de três estudos de caso. Interfacehs - Revista de Gestão Integrada em Saúde do Trabalho e Meio Ambiente, São Paulo, 2(4), ago.

Sousa. M. T S., Paula, M. B., Souza-Pinto, H. (2012) O papel das cooperativas nos canais reversos de pós-consumo. Revista de Administração de Empresas, 52(2), 246-262.

Torres, H. R. (2008) As organizações dos catadores de material reciclável: Inclusão e Sustentabilidade - O caso da associação dos catadores de papel, papelão e material reaproveitável, Asmare, em Belo Horizonte, MG. Brasília - DF, Centro de Desenvolvimento Sustentável, Universidade de Brasília. 138p. Dissertação (Mestrado).

Unced - United National Conference on Environmental and Development (1993). Environmentally sound management of solid wastes and sewage-related issues. In: Agenda 21. (ed. rev.) Recuperado em: 7 jul.2011, de: http://www.un.org/esa/dsd/ agenda21/res_agenda21_21.shtml, abr.

Wilson, D. C., Velis, C., Cheeseman, C. (2006) Role of informal sector recycling in waste management in developing countries. Habitat International, 30,797-808.

Yin, R. K. (2010) Estudo de caso: planejamento e métodos. trad. Ana Thorell. (4.ed.) Porto Alegre: Bookman. 248 p.

Data da submissão: 17/12/2013

Data da publicação: 16/12/2013

Revista de Gestão Social e Ambiental - RGSA, São Paulo, v. 7, n. 3, p. 20-36, out./dez., 2013. 